\title{
A Study on the Prevalence of Diabetes Mellitus Among Students of Hail University
}

\author{
Yomna Ali Moustafa Marzok Elkhateeb ${ }^{1,2,}$, , Norah yousefkhaled Alfhied ${ }^{2}$ \\ ${ }^{1}$ Microbial Chemistry Department, Genetic Engineering and Biotechnology Division, National Research Centre, Giza, Egypt \\ ${ }^{2}$ Clinical Nutrition Department, College of Applied Medical Sciences, University of Hail, Hail, Kingdom of Saudi Arabia
}

\section{Email address:}

yomna_moustafa@yahoo.com (Y.A. M. M. Elkhateeb), y.elkhateeb@uoh.edu.sa (Y. A. M. M. Elkhateeb)

${ }^{*}$ Corresponding author

\section{To cite this article:}

Yomna Ali Moustafa Marzok Elkhateeb, Norah yousefkhaled Alfhied. A Study on the Prevalence of Diabetes Mellitus Among Students of Hail University. International Journal of Biomedical Science and Engineering. Vol. 6, No. 3, 2018, pp. 59-64.

doi: $10.11648 /$ j.ijbse.20180603.11

Received: May 22, 2018; Accepted: September 3, 2018; Published: November 7, 2018

\begin{abstract}
Glucose is the main type of sugar found in blood and main source of energy. Glucose comes from the food and is also made in liver and muscles. Blood carries glucose to all of body's cells to use for energy. Pancreas releases a hormone insulin, into blood. Insulin helps blood carry glucose to all body's cells. Glucose stays in blood and doesn't reach cells when body doesn't make enough insulin or the insulin doesn't work the way it should. Blood glucose levels increased and can cause diabetes or prediabetes. Prediabetes means that the amount of glucose in blood is above normal level but not high enough to be called diabetes. Chances of getting type 2 diabetes are higher with prediabetes. With some weight loss and moderate physical activity, the person can prevent type 2 diabetes. The person can even return to normal glucose levels, possibly without taking any medicines. [13] Diabetes is a group of metabolic diseases characterized by hyperglycemia resulting from defects in insulin secretion, insulin action, or both. Several pathogenic processes are involved in the development of diabetes. [3] The prevalence of type 2 diabetes has risen steadily in recent decades, and type 2 diabetes is now a global health problem. Diabetes causes greater morbidity and mortality. There is increased concern about prevalence of type 2 diabetes in Arabic countries especially Saudi Arabia. [7] Therefore, the current study designed to determine the prevalence of diabetes mellitus among female students in University of Hail; study the association of diabetes mellitus in relation to obesity and using of BMI as a diagnostic tool in the current classification system for obesity.
\end{abstract}

Keywords: Diabetes Mellitus, Type 1Diabetes, Type 2 Diabetes, Gestational Diabetes, Symptoms of Diabetes, Control of Diabetes

\section{Introduction}

Diabetes mellitus is a disorder resulting from a defect in insulin secretion, insulin action, or both. Complications of diabetes mellitus include retinopathy, nephropathy, neuropathy and cardiovascular. $[1,2]$.

There are three main types of diabetes are type 1, type 2 , and gestational diabetes.

\subsection{Type 1 Diabetes}

Called juvenile diabetes, the body cannot produce insulin or enough insulin because immunesystem has attacked and the cells that make insulin destroyed. This disease develops in young people; however, type 1 diabetes can also develop in adults. Treatment for type 1 diabetes includes: insulin injections, Sometimes oral medicines. $[4,13]$

\subsection{Type 2 Diabetes}

Called adult-onset diabetes, can affect people at any age, even children. However, it develops most often in middleaged and older people. It begins with insulin resistance that target tissues are unable to respond to normal circulating concentrations of insulin. As a result the output of insulin from the pancreatic beta-cells is increased (hyperinsulinemia) 
to maintain normal blood glucose levels. Over time, the pancreas cannot produce enough insulin. This leads to impaired glucose tolerance, impaired fasting glycaemia (glucose values above the normal range but below those defined as diagnostic of diabetes). The patient will need to treat type 2 diabetes. [2, 4] Treatment for type 2 diabetes includes: Using diabetes medicines.

\subsection{Gestational Diabetes (GD)}

If the pancreas doesn't make enough insulin during pregnancy, a woman develops gestational diabetes. All women have insulin resistance late in their pregnancy due to production of hormones that can lead to insulin resistance. This condition disappeared after the baby is born but a woman who has had gestational diabetes is more likely to develop type 2 diabetes later in life. Overweight or obesity increase risk of gestational diabetes developement.

\subsection{Symptoms of Diabetes}

Thirsty, urinating often feeling very hungry, tired, losing weight, feelings of pins in feet. These symptoms don't occur in all patients. [13]

\subsection{Control of Diabetes}

Insulin is required for treatment of type 1 diabetes while type 2 diabetes treated with oral medication, Foot care and Other saving interventions include: treatment for retinopathy; Blood lipid control; Screening for early signs of diabetesrelated kidney disease and treatment. These measures should be supported by avoiding tobacco use, regular physical activity (at least 30 minutes of regular on most days to maintain healthy body weight), and a healthy diet. [4] The prevalence of obesity is increasing dramatically worldwide and contributes to the development of non-insulin-dependent (NIDDM) or type 2 diabetes so that weight control efforts are an important component of the clinical management of diabetes. Although epidemiological studies reported that the relationship between obesity and risk of diabetes is causal. $[2,3,8,9]$.

BMI used as a diagnostic tool in the current classification system for obesity. It was found that there is an extremely strong association between BMl and risk of non-insulindependent (NIDDM) or type 2 diabetes. Women with a BMI of 23-25 have a 4-fold higher risk of type 2 diabetes than those with a BMI <20; Those with a BMI 24-25 have a 5fold increased risk, and a BMI $>35$ increases the risk of developing type 2 diabetes 93 -fold. [6]

\section{Methodology}

Study was planned and conducted to evaluate the prevalence of Diabetes mellitus among students of Hail University. Blood glucose level was estimated in blood samples which collected from random sample of 300students from (Applied Medical Science College, Business Administration College and Education College). Subjects were asked to record their self-reported height and weight. Body mass index (BMI), was measured as a diagnostic tool for obesity to study the association of diabetes mellitus in relation to obesity. According to the WHO's classification for BMI, weight status was classified into four categories: underweight $(\mathrm{BMI} \leq 18.5)$, normal weight $(\mathrm{BMI}=18.5-24.9)$, overweight $(\mathrm{BMI}=25-29.9)$, and obese $(\mathrm{BMI} \geq 30)[16]$.

\subsection{Sample Collection}

Blood glucose level was estimated in blood samples which collected from students during the first semester (20162017).

\subsection{Diabetes Mellitus Determination}

Blood glucose level used as a range to determine Diabetes mellitus in the proposed study. The Glucometer used for analysis and gives immediate, digitally displayed results.

\subsection{Statistical Analysis}

Statistical analyses were performed using the Statistical Package for Social Sciences (SPSS) software, Arab Processor in Social Statistics and Mstat-c Program. Descriptive statistics such as means, standard deviations (SD) and ANOVA (one way analysis) according to Snedcor and Cochran (1980) were calculated for the parametric variables, Least significant differences (LSD) were used compare between means according to Waller and Duncan (1969) at probability 0.05 and 0.01 . Non-parametric variables were tested by Chi-square tests. Differences were considered statistically significant at $\mathrm{P}<0.05$ or $\mathrm{P}<0.01$. [11, 12]

\section{Results and Discussion}

Of 300 students participated in the study, 100 students from Applied Medical Science College, 100 students from Business Administration College and100 students from Education College) in age group 18-25 year. Detail of characteristics of participants shown in Table 1.

Table 1. Characteristics of the participants.

\begin{tabular}{lllll}
\hline Variables & Minimum & Maximum & Mean & \\
\hline Age(year) & 18 & 25 & 21.15 & 1.97 \\
Weight $(\mathrm{kg})$ & 45 & 97 & 57.39 & 11.03 \\
Height $(\mathrm{cm})$ & 145 & 166 & 155.67 & 5.12 \\
\hline
\end{tabular}

Table 1 represent that a total of 300 female students participated in the current study. Total mean age \pm SD was $21.15 \pm$ 1.97years (range 18-25). The mean weight and height were respectively $57.39 \pm 11.03 \mathrm{~kg}$ and $155.67 \pm 5.12 \mathrm{~cm}$. Mean BMI $($ mean $\pm \mathrm{SD}=23.44 \pm 4.63)$. 
Table 2. Chi-square level of Blood glucose, social status and weight status.

\begin{tabular}{|c|c|c|c|c|c|}
\hline Variables & Status & $\%$ & $\chi_{\mathrm{t}}^{2}$ at $\alpha=0.01$ & $\chi_{\mathrm{t}}^{2}$ at $\alpha=0.05$ & $\overline{\chi_{c}^{2}}$ \\
\hline Social status & $\begin{array}{l}\text { Single } \\
\text { Married }\end{array}$ & $\begin{array}{l}93 \\
6\end{array}$ & $3.84^{* *}$ & $6.63^{*}$ & 76.45 \\
\hline $\mathrm{BMI}\left(\mathrm{kg} / \mathrm{m}^{2}\right)$ & $\begin{array}{l}\text { Under wt. } \\
\text { Healthy Wt. } \\
\text { Over Wt. } \\
\text { Obese } \\
\text { Severely Wt. }\end{array}$ & $\begin{array}{l}6 \\
66 \\
18 \\
9 \\
0\end{array}$ & $13.28^{* *}$ & $9.49^{*}$ & 143.27 \\
\hline
\end{tabular}

$*$ Significant at $\alpha=0.05$ level and $* *=$ Significant at $\alpha=0.01$ level (highly Significant).

Results from table 2 showed that there is a highly significant difference among levels of blood glucose (hypoglycemia $12 \%$; Normal $57 \%$; prediabetes $24 \%$ and Diabetes $6 \%$ ). Also, there is a highly significant difference in social status and BMI $(9 \%$ obese, $18 \%$ over weight, $66 \%$ healthy weight and $6 \%$ underweight) at $\mathrm{P}<0.05$ or $\mathrm{P}<0.01$.

Table 3. Effect of type of College on Social status.

\begin{tabular}{llllll}
\hline \multirow{2}{*}{ College } & Social status & Married & $\chi_{\mathbf{c}}^{2}$ & $\boldsymbol{\chi}_{\mathbf{t}}^{2}$ at $\boldsymbol{\alpha}=\mathbf{0 . 0 5}$ & \multirow{2}{*}{$\boldsymbol{\chi}_{\mathbf{t}}^{2}$ at $\boldsymbol{\alpha}=\mathbf{0 . 0 1}$} \\
\cline { 2 - 5 } & Single & 3 & & & \\
\hline Applied Medical Science & 30 & 0 & 9.21 & 5.99 & 3.19 \\
Business Administration & 33 & 3 & & & \\
Education & 30 & & & \\
\hline
\end{tabular}

Results from Table 3 showed that there is a nonsignificant difference in social status between three Colleges. Type of College has not any effect on social status.

Table 4. Effect of type of College on weight status.

\begin{tabular}{|c|c|c|c|c|c|c|}
\hline \multirow{2}{*}{$\begin{array}{l}\text { Weight status } \\
\left(\mathrm{kg} / \mathrm{m}^{2}\right)\end{array}$} & \multicolumn{3}{|l|}{ College } & \multirow{2}{*}{$\chi_{\mathrm{c}}^{2}$} & \multirow{2}{*}{$\chi_{\mathrm{t}}^{2}$ at $\alpha=0.05$} & \multirow{2}{*}{$\chi_{\mathrm{t}}^{2}$ at $\alpha=0.01$} \\
\hline & Applied & Business & Education & & & \\
\hline Under wt. & 6 & 0 & 0 & & & \\
\hline Healthy Wt. & 27 & 33 & 6 & & & \\
\hline Over Wt. & 0 & 0 & 18 & $20.9^{* *}$ & $15.51^{*}$ & 84.27 \\
\hline Obese & 0 & 0 & 9 & & & \\
\hline Severely Wt. & 0 & 0 & 0 & & & \\
\hline
\end{tabular}

Table 4 represent that there is a highly significant difference in weight status among colleges. It was found that $(27 \%$,from Applied college, $33 \%$ from Business college and $6 \%$ from Education college) have Healthy weight and
$6 \%$ from Applied college was under weight, but only $9 \%$ from Education college was Obese at $\mathrm{P}<0.05$ or $\mathrm{P}<0.01$. Type of College has a significant effect on weight status.

Table 5. Effect of type of College on Blood glucose level.

\begin{tabular}{|c|c|c|c|c|c|c|}
\hline \multirow{2}{*}{ Glucose level (mg/dL) } & \multicolumn{3}{|l|}{ College } & \multirow{2}{*}{$\chi_{c}^{2}$} & \multirow{2}{*}{$\chi_{\mathrm{t}}^{2}$ at $\alpha=0.05$} & \multirow{2}{*}{$\chi_{\mathrm{t}}^{2}$ at $\alpha=0.01$} \\
\hline & Applied & Business & Education & & & \\
\hline Hypoglycemia & 12 & 0 & 0 & \multirow{4}{*}{$16.81^{* *}$} & \multirow{4}{*}{$12.59^{*}$} & \multirow{4}{*}{108} \\
\hline Normal & 21 & 33 & 3 & & & \\
\hline Prediabetes & 0 & 0 & 24 & & & \\
\hline Diabetes & 0 & 0 & 6 & & & \\
\hline
\end{tabular}

$\chi_{\mathrm{t}}^{2}=$ Chi square tabulated and $\chi_{\mathrm{c}}^{2}=$ Chi square calculated.

Table 5 represent that there is a highly significant difference in blood glucose level among colleges. It was found that $(21 \%$, from Applied college, $33 \%$ from Business college and 3\% from Education college) have normal blood glucose level and $12 \%$ from Applied college was hypoglycemia, but only $24 \%$ from Education college was prediabetes at $\mathrm{P}<0.05$ or $\mathrm{P}<0.01$. Type of College has a significant effect on blood glucose level. This result is supported by study conducted by Ibrahim Abdelmajeed
Ginawiet al who found that the prevalence rates of DM in Hail, Baqaa, Ash Shinan and Ghazala were 27\%, 35\%, $18.6 \%$ and $35 \%$, respectively. Another study showed that the prevalence of diabetes in general Saudi population was 30\% (Khalid, et al. 2011). While Mansour, et al (2004) reported an overall prevalence of DM of $23.7 \%$ in KSA, with the highest prevalence rates were among the Northern Saudi population of $27.9 \%$ followed by the Eastern region of $26.4 \%$, then Saudis from the Western region of $24.7 \%$, and from the 
Central region of $23.7 \%$, whereas the lowest prevalence was from the Southern region of $18.2 \%$.

Table 6. Comparison among studied traits in different colleges Applied Medical Science, Business Administration and Education."

\begin{tabular}{lllll}
\hline College & Weight $\mathbf{( K g )}$ & Height $\mathbf{( c m )}$ & BMI $(\mathbf{k g} / \mathbf{m} 2)$ & Blood glucose $(\mathbf{m g} / \mathbf{d l})$ \\
\hline -Applied Medical Science & $49.82 \pm 3.63 \mathrm{~b}$ & $159.27 \pm 4.22$ & $19.62 \pm 0.88 \mathrm{c}$ & $75.09 \pm 9.17 \mathrm{c}$ \\
-Business Administration & $53.64 \pm 3.91 \mathrm{~b}$ & $156.09 \pm 5.13$ & $22.00 \pm 0.79 \mathrm{~b}$ & $93.45 \pm 4.01 \mathrm{~b}$ \\
-Education & $68.73 \pm 11.87 \mathrm{a}$ & $154.64 \pm 5.24$ & $28.70 \pm 4.30 \mathrm{a}$ & $111.09 \pm 10.03 \mathrm{a}$ \\
LSD at $\alpha$ 0.05 level & 6.541 & N.s & 2.241 & 7.125 \\
Applied Medical Science & $49.82 \pm 3.63 \mathrm{~b}$ & $159.27 \pm 4.22$ & $19.62 \pm 0.88 \mathrm{~B}$ & $75.09 \pm 9.17 \mathrm{c}$ \\
Business Administration & $53.64 \pm 3.91 \mathrm{~b}$ & $156.09 \pm 5.13$ & $22.00 \pm 0.79 \mathrm{~b}$ & $93.45 \pm 4.01 \mathrm{~b}$ \\
Education & $68.73 \pm 11.87 \mathrm{a}$ & $154.64 \pm 5.24$ & $28.70 \pm 4.30 \mathrm{a}$ & $111.09 \pm 10.03 \mathrm{a}$ \\
LSD at $\alpha 0.01$ level & 8.807 & N.s & 3.018 & 9.595 \\
\hline
\end{tabular}

N.s $=$ Non-significant The means followed by the same alphabetical letters were not significantly different at the probability level of 0.05 and 0.01 .

Table 6. represent the Comparison among studied traits in different Colleges Applied Medical Science, Business Administration and Education; the results show that there is a highly significant difference in blood glucose level among Colleges. It was found that students from Education college have the highest blood glucose level which was $111.09 \mathrm{mg} / \mathrm{dl}$ (within the range of prediabetes; they have a risk to be diabetic. Applied Medical Science and Business Administration have blood glucose level within normal.
The results show that there is a highly significant difference in BMI and Weight among Colleges. It was found that students from Education College have the highest weight and BMI which was 28.7 (within the range of overwieght; they have a risk to be obese) while Applied Medical Science and Business Administration have BMI (19.62 and 22) respectively which was within normal weight. In respect to height, there is no significant difference between Colleges at $\mathrm{P}<0.05$ or $\mathrm{P}<0.01$. Type of College has a significant effect on blood glucose level.

Table 7. Simple Correlation (r) between Studiedtraits.

\begin{tabular}{llll}
\hline Variables & Weight $(\mathbf{K g})$ & Height $(\mathbf{c m})$ & BMI $\left(\mathbf{k g} / \mathbf{m}^{2}\right)$ \\
\hline Blood glucose $(\mathrm{mg} / \mathrm{dl})$ & $0.828^{* *}$ & -0.278 & $0.891^{* *}$ \\
BMI $\left(\mathrm{kg} / \mathrm{m}^{2}\right)$ & $0.939^{* *}$ & -0.277 & \\
Height $(\mathrm{cm})$ & 0.064 & & \\
\hline
\end{tabular}

$*=$ Significant at $\alpha 0.05$ level $* *=$ Significant at $\alpha 0.01$ level (Highly Significant)

Table 7 represent the correlation between studied traits (Blood glucose level, BMI and weight); the results show that the correlation between blood glucose level and weight was highly significant. Also the correlation between blood glucose level and BMI was highly significant. Students with high BMI within range of overweight or obese will be in risk of diabetes.

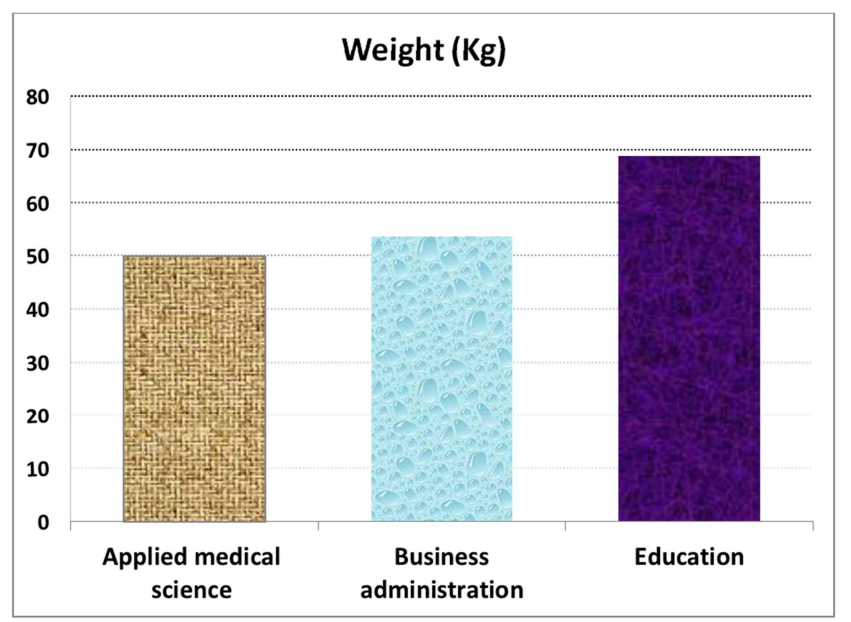

Figure 1. Weight $(\mathrm{kg})$ average of Colleges students "Applied Medical Science, Business Administration and Education".

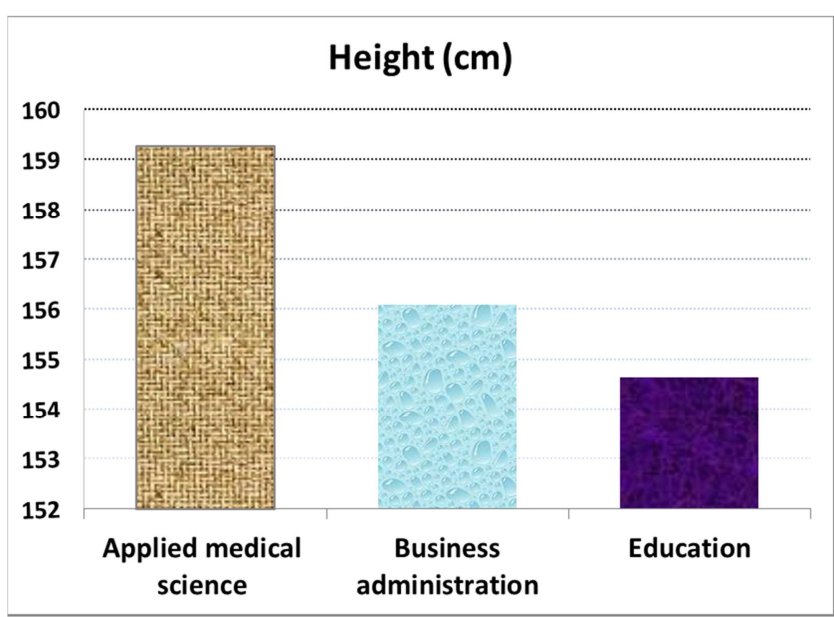

Figure 2. Height (cm) average of Colleges students "Applied Medical Science, Business Administration and Education".

The present results supported by a study conducted by Maria, et al. (2001) who established the relationship between obesity and diabetes. Another study from KSA conducted by ALShahrani and Al-Khaldi (2013) to assess the effect of overweight and obesity on diabetes and hypertension reported that the prevalence of obesity among diabetics and hypertensive patients was $46 \%$ and $54 \%$, respectively. 


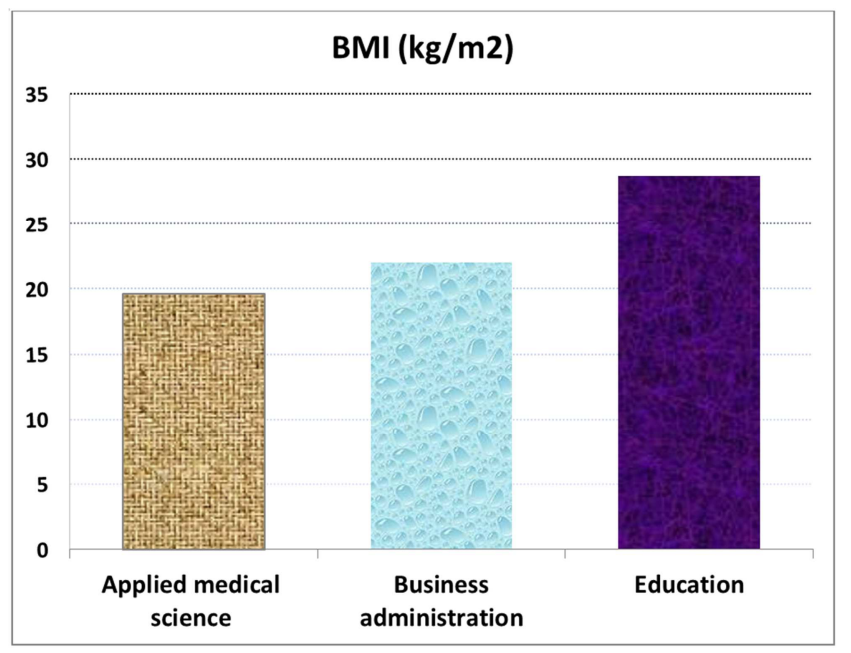

Figure 3. BMI $\left(\mathrm{Kg} / \mathrm{cm}^{2}\right)$ average of Colleges students Applied Medical science, Business Administration and Education."

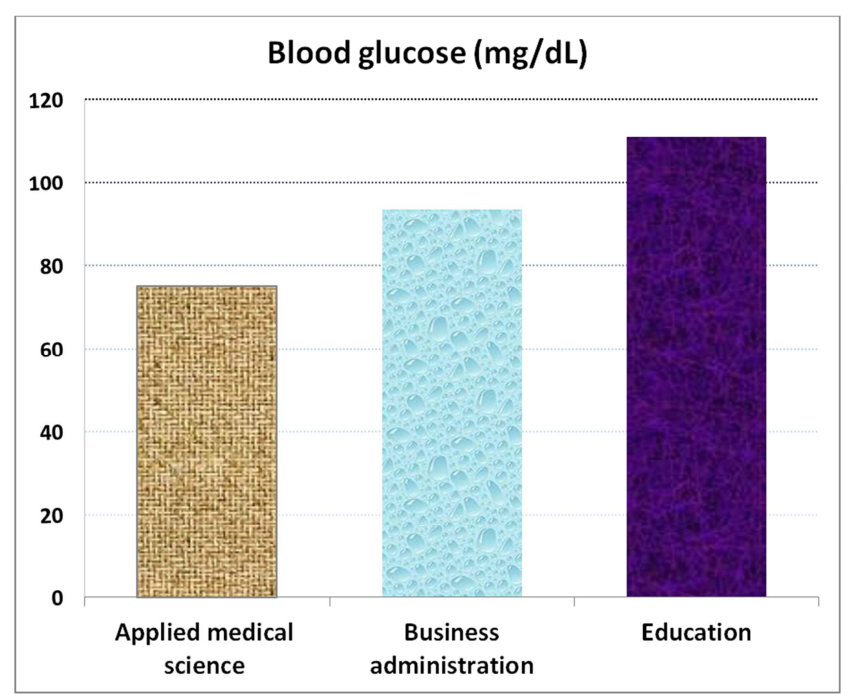

Figure 4. Blood glucose (mg/dl) average of Colleges students Applied Medical Science, Business Administration and Literary and Education."

\section{Conclusion and Recommendation}

Type $2 \mathrm{DM}$ is due primarily to lifestyle factors and genetics. A number of lifestyle factors are known to be important to the development of type 2 DM. These are physical inactivity, sedentary lifestyle, cigarette smoking and generous consumption of alcohol. Obesity has been found to contribute to approximately $55 \%$ of cases of type 2 DM. [1, 20, 21].

In the current study, results of statistical analysis indicate that:

-All students have Healthy weight except 9\% from Education College was Obese.

-All students have normal blood glucose level except $24 \%$ from Education College was prediabetes.

-Students from Education College have the highest blood glucose level which was $111.09 \mathrm{mg} / \mathrm{dl}$ (within the range of prediabetes) and they have a risk to be diabetic. Students of Applied Medical Science and Business Administration have blood glucose level within normal.
-Students from Education College have the highest weight and BMI which was 28.7 (within the range of overweight) and they have a risk to be obese while Applied Medical Science and Business Administration have BMI within normal weight. Results reflect that students of Education College have poor nutritional knowledge. The results showed that the correlation between blood glucose level and BMI was highly significant. Students with high BMI within range of overweight or obese will be in risk of diabetes.

Finally, we conclude that there is a strong correlation between Diabetes and Obesity. Health Education program regarding good food choice and physical exercise is required because type 2 $\mathrm{DM}$ is a metabolic disease that can be prevented through lifestyle modification, diet control, and control of overweight and obesity. Patients with type 2 DM should receive a medical nutrition evaluation and lifestyle recommendations according to physical and functional ability.

\section{References}

[1] Abdulfatai B. Olokoba, Olusegun A. Obateru and Lateefat B. Olokoba. Type 2 Diabetes Mellitus: A Review of Current Trends. Oman Medical Journal 2012;27( 4): 269-273 .

[2] Kevin Knight, Enkhe Badamgarav, James M. Henning Vic Hasselblad, Anacleto D. Gano, Joshua J. Of man, and Scott R. Weingarten. A Systematic Review of Diabetes Disease Management Programs, The American Journal Of Managed Care. 2005;11:242-250.

[3] Logue, J; Walker, JJ; Leese, G, Lindsay, R; McKnight, J; Morris, A; Philip, S; Wild, S; Sattar, N \& on behalf of The Scottish Diabetes Research Network Epidemiology Group. The Association Between BMI Measured Within a Year After Diagnosis of Type 2 Diabetes and Mortality. Diabetes Care. 2013; 36:887-893.

[4] WHO. Diabetes, NMHF act Sheet, 2010. Availableat: (http://www.who.int/mediacentre/factsheets/fs312/en/)

[5] Srinivasan K. Plant foods in the management of diabetes mellitus: spices as beneficial antidiabetic food adjuncts. Int J Food SciNutr. 2005;56(6): 399-414.

[6] A. Astrup and N. Finer. Redefining Type 2 diabetes: 'Diabesity' or 'Obesity Dependent Diabetes Mellitus'?, International Association for the Study of Obesity. 2000; 1: 57-59 .

[7] George A Bray, Kathleen A Jablonski, Wilfred Y Fujimoto. Relation of central adiposity and body mass index to the development of diabetes in the Diabetes Prevention Program. Am J Clin Nutr. 2008; 87:1212- 1218.

[8] JUNE M. CHAN, ERIC B. RIMM, GRAHAM A. Colditz, MEIR J. STAMPFER and WALTER C. WILLETT.

[9] Obesity, Fat Distribution, and Weight Gain as Risk Factors for Clinical Diabetes in Men, Diabetes Care. 1994;17(9):961-969

[10] Javier Gómez-Ambrosi, Camilo Silva, Juan C. Galofré, Javier Escalada, Silvia Santos, María J. Gil, Victor Valent, Fernando Rotellar, Beatriz Ramírez, Javier Salvador and Gema Frühbeck. Body Adiposity and Type 2 Diabetes: Increased Risk With a High Body Fat Percentage Even Having a Normal BMI, Obesity. 2011; 19(7):1439-1444. 
[11] Amy R. Weinstein, Howard D., I. Min Lee, Nancy R. Cook, JoAnn E. Manson, Julie E. Buring and J. Michael Gaziano. Relationship of Physical Activity vs Body Mass Index With Type 2 Diabetes in Women. JAMA. 2004; 292(10):11881194.

[12] Snedecor, G. W. and W. G. Cochran (1980). Statistical Methods, 7th ed. Iowa State Unive. Press, Iowa, USA.

[13] Waller, A. and D. B. Duncan. Multiple range and multiple test. Biometries. 1969; 11: 1-24.

[14] Richard F. Hamman, RENA R. Wing, Sharon L. Edelstein, John M. Lachin, George A. Bray, Linda Delahanty, Mary Hoskin, Andrea M. Kriska, Elizabeth J. Mayer-davis, Xavier PI-Sunyear, Judith Regensteiner, Beth Venditti, JudithwylieRosett,For The Diabetes Prevention Program Research Group. Effect of Weight Loss With Lifestyle Intervention on Risk of Diabetes. Diabetes Care. 2006; 29:2102-2107.

[15] Ibrahim Abdelmajeed Ginawi ; Abdelbaset Mohamed Elasbali; Hussain Gadelkarim Ahmed; Awdah M. Al-hazimi; Hassan Kasim Haridi; Ibraheem M. Ashankyty; Abdelkareem Alsuedaa; Daad Akbar; Fatma Albeladi and Ahmed Alrashdan. Prevalence Rates of Diabetes and Obesity in 4 Provincesin Hail Region, KSA. Egypt. Acad. J. Biolog. Sci. 2014; 6(2): 47-53.
[16] Hauner H. Managing type 2 diabetes mellitusin patients with obesity. Treat Endocrinol. 2004;3(4):223-32.

[17] WHO Media centre. Obesity and overweight. Geneva, World Health Organization, 2013. Available at: http://www.who.int/mediacentre/factsheets/fs311/en/

[18] Mansour M. Al-Nozha, Mohammed A. Al-Maatouq, Yaqoub Y. Al-Mazrou. Diabetes mellitus in Saudi Arabia. Saudi Med J. 2004; 25 (11): 1603-1610.

[19] Khalid A. Alqurashi, Khalid S. Aljabri, and Samia A. Bokhari. Prevalenceofdiabetes mellitus in a Saudicommunity. Ann Saudi Med. 2011; 31(1): 19-23.

[20] AL-ShahraniAM, Al-Khaldi YM. Obesityamong diabetic and hypertensivepatients in Aseerregion. SaudiArabia. Saudi J Obesity 2013; 1:14-7.

[21] American Diabetes Association. Obesity Management for the Treatment of Type 2 Diabetes. Standards of Medical Care in Diabetes2018 Jan; 41(Supplement 1): S65-S72. https://doi.org/10.2337/dc18-S007

[22] Gerald H T, Daphne O. Diet, Obesity and Diabetes. Archives of Diabetes \& Obesity. 2018:1(1):14-16. 